International Journal of Current Advanced Research

ISSN: O: 2319-6475, ISSN: P: 2319 - 6505, Impact Factor: SJIF: 5.995

Available Online at www.journalijcar.org

Volume 6; Issue 4; April 2017; Page No. 3451-3454

DOI: http://dx.doi.org/10.24327/ijcar.2017.3454.0291

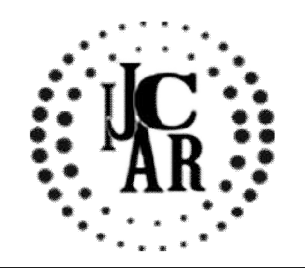

Research Article

\title{
EFFICACY OF POVIDONE IODINE VS HYDROGEN PEROXIDE AS DENTURE DISINFECTANTS- IN VITRO STUDY
}

\author{
Fathima Mariyam Niyas., Preetham Prasad Nittla., Muralidharan and Varshitha A
}

Saveetha Dental College, Saveetha University, Chennai

\begin{tabular}{|c|c|}
\hline 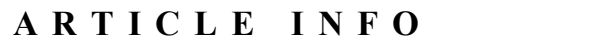 & $A B S T R A C T$ \\
\hline Article History: & \multirow{4}{*}{$\begin{array}{l}\text { Hydrogen peroxide is a widely used antimicrobial agent. It is used in both liquid and gas } \\
\text { form for preservative, disinfection and sterilization applications. Its advantages include its } \\
\text { potent and broad spectrum antimicrobial activity, flexibility in use, and safety profile in } \\
\text { comparison to other microbiocides. Hydrogen peroxide has been shown to be effective } \\
\text { against all forms of microorganisms, including dormant forms of known high resistance } \\
\text { such as bacterial spores and protozoal cysts, and also infectious proteins such as prions } \\
\text { depending on the specific use of the chemical. Povidone iodine is recognized as an } \\
\text { effective broad spectrum biocidal agent, whose in vitro biocidal activity has been studied } \\
\text { for years against bacteria, yeast, mould viruses, fungi, protozoa, actinomycetes and } \\
\text { rickettsia. Typical iodine solutions present significant oral toxicity, but this complex } \\
\text { exhibits markedly lower toxicity, being less hazardous in case of accidental ingestion. The } \\
\text { results obtained from both methods were consistent with each other. When tested against the } \\
\text { two controls, it was found that both disinfectants had similar disinfecting properties. }\end{array}$} \\
\hline $\begin{array}{l}\text { Received } 8^{\text {th }} \text { January, } 2017 \\
\text { Received in revised form } 10^{\text {th }} \text { February, } 2017 \\
\text { Accepted } 22^{\text {nd }} \text { March, } 2017 \\
\text { Published online } 28^{\text {th }} \text { April, } 2017\end{array}$ & \\
\hline Key words: & \\
\hline $\begin{array}{l}\text { Povidone Iodine, Hydrogen Peroxide, Biocide, } \\
\text { Denture Disinfectant }\end{array}$ & \\
\hline
\end{tabular}

Copyright $\bigcirc 2017$ Fathima Mariyam Niyas et al. This is an open access article distributed under the Creative Commons Attribution License, which permits unrestricted use, distribution, and reproduction in any medium, provided the original work is properly cited.

\section{INTRODUCTION}

A complete denture is defined as a dental prosthesis, which replaces the entire dentition and associated structures of the maxilla and mandible ${ }^{[1] .}$ A complete denture restores the aesthetic, phonetic and masticatory functions of the individual. A denture placed in the oral environment forms a biofilm on the surfaces of the denture, which makes it susceptible for infections ${ }^{[2]}$. Patients who wear dentures present with a variety of symptoms and abnormal intraoral findings ${ }^{[3]}$. The advancing age of the denture wearer and the nature of the denture bearing mucosa appear to influence the nature of the problem. Superimposed infection with candidial organisms and traumatic lesions are the most commonly encountered abnormalities. Denture stomatitis had been reported in $11-67 \%$ of complete denture wearers ${ }^{[4]}$. Denture biofilm is an important factor in in the pathogenesis of denture stomatitis. Candidia albicans found in the biofilm has been reported as an important agent for the installation and maintenance of denture stomatitis ${ }^{[5]}$. The prevalence of Candida albicans in the denture is significantly higher than that in mucosa. In healthy individuals it has a prevalence rate of $45-65 \%$ with a higher in children and young adults. In denture wearers the prevalence of candida increases to 60$100 \%$ due to the decreased flow of oxygen and saliva caused by the denture to the underlying tissue producing a local

*Corresponding author: Fathima Mariyam Niyas

Saveetha Dental College, Saveetha University, Chennai acidic and anaerobic micro-environment that favors yeast overgrowth ${ }^{[6]}$. Candida species are yeasts and within the oral cavity. It is one of the main causative organisms of dentureinduced stomatitis which is primarily due its ability to adhere and form biofilms on oral cavity tissues and denture surfaces as well as due to its resistance to anti-fungal agents ${ }^{[7]}$. This biofilm grows extensively on acrylic resin denture material and its effective removal is a significant challenge by both chemical and mechanical methods. Dentures can be cleaned mechanically, chemically or through a combination of both these methods. Mechanical methods are comprised of brushing, and ultrasonic treatment though the use of ultrasonic cleansers ${ }^{[8]}$. The ultrasonic cleaning method is limited due to the lack of information and discouraging cost. Brushing is easier, inexpensive and an effective method when used methodically in removing denture biofilm. However, abrasive action could result in the wear of the denture base and relining materials ${ }^{[9]}$. Another disadvantage of the mechanical methods is among the physically challenged or geriatric denture wearers. So efficient chemical denture cleansers might be an important alternative or adjunctive to mechanical cleansing. Chemical methods include soaking the dentures in commercial (peroxides, acids, mouth washes and enzymes) or household (hypochlorides, sodium chloride vinegar) products ${ }^{[10]}$. These chemicals are easy to use and can easily reach undercuts of the denture base which are otherwise overlooked during denture cleaning. The acrylic resins surface roughness remains unchanged compared to the abrasion due 
to brushing and the surfaces are less susceptible to biofilm accumulation $^{[11]}$.

Hydrogen peroxide is a clear colorless liquid with no odor. Molecular formula is $\mathrm{H}_{2} \mathrm{O}_{2}$. It is an extremely strong oxidizing agent [11]. Hydrogen peroxide is a widely used antimicrobial agent. It is used in both liquid and gas form for preservative, disinfection and sterilization applications ${ }^{[12]}$. Its advantages include its potent and broad spectrum antimicrobial activity, flexibility in use, and safety profile in comparison to other microbiocides ${ }^{[13]}$. Hydrogen peroxide has been shown to be effective against all forms of microorganisms, including dormant forms of known high resistance such as bacterial spores and protozoal cysts, and also infectious proteins such as prions depending on the specific use of the chemical ${ }^{[14]}$. It also has advantages with regard to its toxicity and environmental profile. The general mechanisms of action of $\mathrm{H}_{2} \mathrm{O}_{2}$ significantly reduce any risk of development of resistance to the biocide over time, unlike many other types of anti-infective drugs or biocides ${ }^{[15]}$.

Povidone iodine is recognized as an effective broad spectrum biocidal agent, whose in vitro biocidal activity has been studied for years against bacteria, yeast, mould viruses, fungi, protozoa, actinomycetes and rickettsia ${ }^{[16]}$. Typical iodine solutions present significant oral toxicity, but this complex exhibits markedly lower toxicity, being less hazardous in case of accidental ingestion ${ }^{[17]}$. Povidone iodine has been mostly used for surgical scrubbing and as a prophylactic irrigation solution against surgical site infection. A study has also been demonstrated that at $2.5 \%$ povidone iodine is able to completely exhibit yeast adherence, suggesting that it could be a good candidate in prevention of candidoses ${ }^{[18]}$.

There are many known denture disinfectants such a EDTA, sodium hypochlorite, sodium perborate, povidone iodine, hydrogen peroxide, etc. In this study we have chosen to study the effectiveness of the very commonly available agents, namely povidone iodine and hydrogen peroxide ${ }^{[19]}$.

\section{METHODOLOGY}

The effect of disinfectant was tested by two methods. One was by contamination of denture bases with candida suspension and the second method was by testing the effect of the standardized concentration of disinfectant in a broth.

\section{Sample fabrication}

A total of 40 heat-polymerized acrylic denture strips were obtained from a wax pattern with a standardized dimension of $5 \times 1 \mathrm{~cm}$. The wax pattern was invested with dental stone (type III gypsum) in a metallic flask. After the setting of dental stone, dewaxing is done by immersing the flask in a water bath at a temperature of $70-80^{\circ} \mathrm{C}$ for about 10 minutes ${ }^{[20]}$. Heat-polymerized acrylic resin was mixed according to the manufacturers recommendation and packed into the mold at the dough stage. The metal flask was then closed and subjected to a short curing cycle at $74^{\circ} \mathrm{C}$ for 2 hours followed by a terminal boiling at $100^{\circ} \mathrm{C}$ for 1 hour ${ }^{[21]}$. On completion of curing cycle, the flask was allowed to completely cool before opening and the denture sample was obtained. The denture strips of $5 \times 1 \mathrm{~cm}$ dimension were checked for any imperfections. The cameo surface of the strips were sandpapered and polished ${ }^{[21]}$. On completion of processing, the strips were packed and autoclaved.

\section{Contamination of specimen}

40 heat cured denture acrylic denture strips were selected and sterilized by autoclaving at $15 \mathrm{lbs}$ for 30 minutes. These denture strips were immersed in sterilized uricol containers containing $50 \mathrm{ml}$ of sterilized artificial saliva. A Candida albicans suspension was made to the turbidity matching 0.5 Mcfarland standard by immersing for 30 minutes. $100 \mu 1$ of suspension is added to the artificial saliva and well shaken to ensure a good mix. The denture strips in the above suspension was incubated for 3 days at $37^{\circ}$ Celsius after which it was taken out, and cleaned with mineral water and then immersed in $50 \mathrm{ml}$ of disinfectant and kept for 6 hours. A subculture was made on Brain Heart Infusion agar and incubated for 24 hours.

\section{Preparation of disinfectants}

Commercially available oxidising agent $5 \%$ hydrogen peroxide and $5 \%$ povidone iodine were used as denture cleansing agents in this study. Saline was taken as the negative control and $0.2 \%$ chlorhexidine containing commercially available mouthwash was taken as the positive control. After incubation for 48 hours, the denture samples were washed in drinking water and placed in a sterile container containing denture cleansing agent. 10 denture samples were placed in each denture cleansing agent (hydrogen peroxide and povidone iodine). The denture samples were left in the denture cleansing agent for 6 hours.

\section{Culture preparation}

After 6 hours, a swab was taken from the rough surface of the denture base sample and streak on the SDA plate. Repeat this for all the denture base samples. Incubate the SDA plates for 24 hours. After 24 hours, the growth pattern of Candida albicans was observed.

\section{Broth culture}

The disinfectant material is taken in a standardized concentration in 5 curettes of $1 \mathrm{ml}$ each, the candida suspension which was made with turbidity matching 0.5 McFarland standard is taken and 10 microliter of the suspension is added to disinfectants taken in cuvette. It was allowed to react for 6 hours at room temperature. After the 6 hour period 10 microliter of this preparation was transferred to saborauds dextrose agar and incubated for 12 hours at 37 degrees Celsius. The test was done along with a positive and a negative control.

\section{Experimental and control groups}

Four groups each containing contaminated specimen of 10 were assigned to various disinfectants.

Group I: Clorhexidine 0.2\% (Positive control)

Group 2: Saline (Negative control)

Group 3: Povidone iodine 5\%

Group 4: Hydrogen peroxide 5\%

\section{RESULTS}

The results obtained from both methods were consistent with each other. When tested against the two controls, it was found that both disinfectants had similar disinfecting properties. 


\begin{tabular}{ccc}
\hline $\begin{array}{c}\text { Denture Cleansing } \\
\text { agent }\end{array}$ & Positive & Negative \\
\hline Hydrogen peroxide & 3 & 7 \\
$5 \%$ & 4 & 6 \\
Povidone iodine $5 \%$ & 10 & 0 \\
Saline & 0 & 10 \\
Chlorhexidine $0.2 \%$ & \\
\hline
\end{tabular}
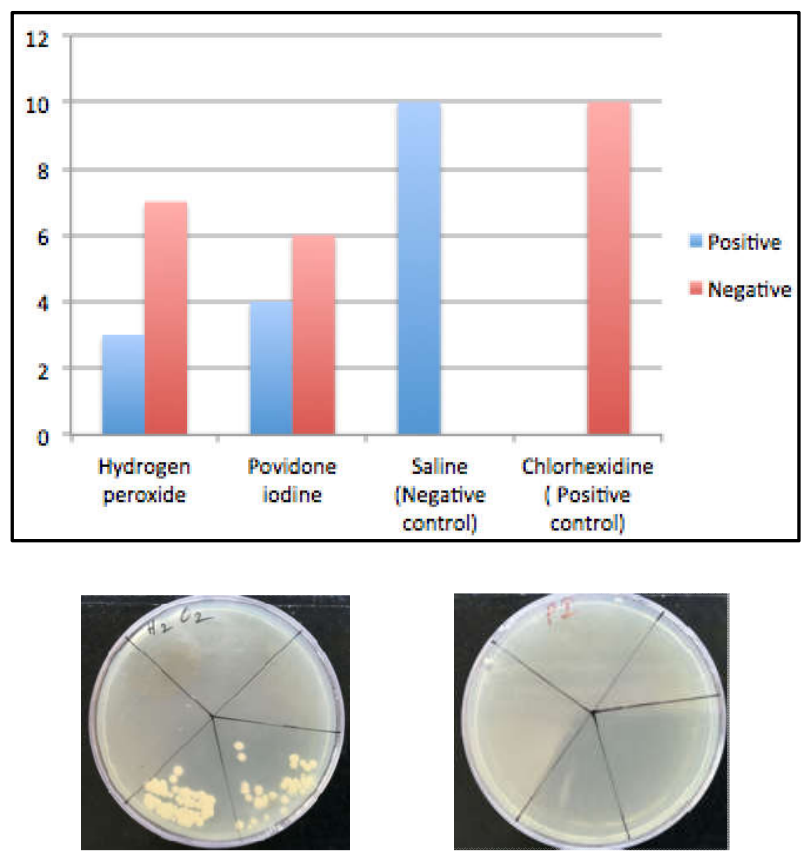

Hydrogen peroxide $5 \%$

Povidone Iodine 5\%

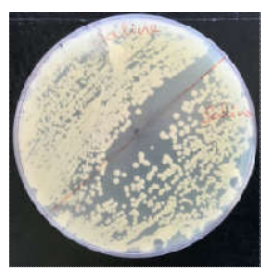

Saline

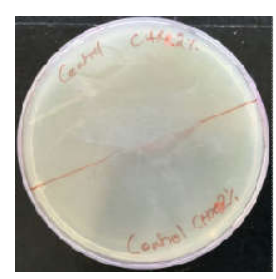

Chlorhexidine $0.2 \%$

\section{CONCLUSION}

Hence of the selected agents, three strips showed positive candidial growth for Hydrogen peroxide and four strips showed positive candidial growth for povidone iodine concluding that both agents are effective denture cleansers.

\section{DISCUSSION}

Povidone iodine is recognized as an effective broad-spectrum biocidal agent, whose in vitro biocidal activity has been studied for years against bacteria, yeast, mold, viruses, fungi, protozoa, actinomycetes and rickettsia ${ }^{[16]}$. Understanding the action of iodine containing disinfectants requires study of the behavior of iodine in aqueous or alcoholic solution ${ }^{[22]}$. Iodophors (complexes associating iodine with a carrier agent) are also listed as iodine-containing products ${ }^{[23]}$. Iodine acts by decreasing the oxygen requirements of aerobic microorganisms. Iodine interferes at the level of the respiratory chain of microorganisms by blocking the transport of electrons through the electrophilic reactions with the enzyes of the respiratory chain ${ }^{[24]}$. Iodine also interacts particularly with the proteins of the cytoplasm membrane in a form with positive $\left(\mathrm{H}_{2} \mathrm{O}+\mathrm{I}\right)$ or neutral $\left(\mathrm{I}_{2}\right.$ or $\left.\mathrm{HOI}\right)$ charge ${ }^{[25]}$.

Hydrogen peroxide is a widely used antimicrobial agent.

Hydrogen peroxide has been shown to be effective against all forms of microorganisms, including dormant forms of known high resistance such as bacterial spores and protozoal cysts, and also infectious proteins such as prions depending on the specific use of the chemical ${ }^{[26]}$. Peroxides play an important part in degrading the bacterial cell. In the presence of oxidizing agents such as peroxides, some organisms defend themselves by producing enzymes which either destroy the oxidizing agent before microbial degradation takes place or help the restoring mechanisms ${ }^{[27]}$. Oxidized molecules are more sensitive to proteolysis than other molecules, and it has been suggested that a 'system of cell sanitization' may enter into effect under the action of an oxidizing agent such as $\mathrm{H}_{2} \mathrm{O}_{2}$ [27].

Both disinfectants are equally effective against candida growth as per the obtained results. Denture wearers will be keen on maintaining denture hygiene if the denture cleansing products are feasible and easily available. The commercially available denture cleansers may be unfeasible to the patient and this may them to neglect denture hygiene. The two disinfectants used in the study fulfill these criteria as they are cost effective, easily available and they have the ability to effectively disinfect a denture. For best results, mechanical cleansing of the denture using toothbrush or nailbrush should be done prior to chemical disinfection ${ }^{[28]}$. Nikawa and coworkers have concluded a similar result that chemical agents are easier to use and their efficacy in reducing biofilm formation ${ }^{[29]}$.

The study was performed with a small sample size as a pilot study, and it leads the way to more large-scale studies with various other cost efficient disinfectants with minimal changes in the color and roughness of the denture surface.

\section{References}

1. Sharry JJ. Complete Denture Prosthodontics, 3rd ed. New York: Blakiston; 1974: 191-210.

2. The Health and Social Care Information Centre. Adult dental health survey 2009. London: Department of Health, 2010.

3. Jeganathan S, Lin C. Denture stomatitis: a review of the aetiology, diagnosis and management. Aust Dent $J$ 1992; 37:107-114

4. Theilade E, Budtz-Jorgensen E. Predominant cultivable microflora of plaque on removable dentures in patients with denture induced stomatitis. Oral Microbiol Immunol 1988; 3:8-13

5. Dorey JL, Blasberg B, MacEntee MI, Conklin RJ. Oral mucosal disorders in denture wearers. J ProsthetDent. 1985; 53(2):210-3

6. Fungal biofilms and related infections advances in Microbiology, Infectious Diseases and Public Health Volume 3 page 89

7. Silva M, Vergani C, Giampaolo E, Neppelenbroek K, Spolidorio D, Machado A. Effectiveness of microwave irradiation on the disinfection of complete dentures. Int J Prosthodont 2006; 19:288-293

8. Sanita' P, Vergani C, Giampaolo E, Pavarina A, Machado A. Growth of Candida species on complete dentures: effect of microwave disinfection. Mycoses 2009; 52:154-160

9. Lal K, Santarpia RP 3rd, Pollock J, Renner R. Assessment of antimicrobial treatment of denture 
stomatitis using an in vivo replica model system: therapeutic efficacy of an oral rinse. $J$ Prosthet Dent 1992; 67:72-77

10. Senna P, Sotto-Maior B, Silva W, Del Bel Cury A. Adding denture cleanser to microwave disinfection regimen to reduce the irradiation time and the exposure of dentures to high temperatures. Gerodontology 2013; 30:26-31

11. Senna P, da Silva W, Cury A. Denture disinfection by microwave energy: influence of Candida albicans biofilm. Gerodontology 2012; 29:186-191

12. T Asad, AC Watkinson, R Hugget. The effects of various disinfectant solutions on the surface hardness of an acrylic resin denture base material. Int $J$ Prosthodont. 1993;6(1):9-12.

13. JJ Lin, SM Cameron, DA Runyan, DW Craft. Disinfection of denture base acrylic resin. J Prosthet Dent. 1999;81(2):202-206.

14. JA Bell, SL Brockmann, DA Sackuvich. Effectiveness of two disinfectants on denture base acrylic resin with an organic load. J Prosthet Dent. 1989;61(5):580-583.

15. Gerard McDonnell. The use of hydrogen peroxide for disinfection and sterilization applications. 2014; DOI: 10.1002/9780470682531.pat0885

16. Darouiche RO, Wall MJ, Jr, Itani KM, Otterson MF, Webb AL, Carrick MM, et al. Chlorhexidine-Alcohol versus Povidone-Iodine for surgical-site antisepsis. $N$ Engl J Med. 2010; 362:18-26.

17. Suwanpimolkul G, Pongkumpai M, Suankratay C. A randomized trial of $2 \%$ chlorhexidine tincture compared with $10 \%$ aqueous povidone-iodine for venipuncture site disinfection: Effects on blood culture contamination rates. $J$ Infect. 2008; 56:354-9.
18. Mimoz O, Karim A, Mercat A, Cosseron M, Falissard B, Parker F, et al. Chlorhexidine compared with povidone-iodine as skin preparation before blood culture. Ann Intern Med. 1999;131:834-7.

19. D.C. Jagger, A. Harrison. Denture cleansing - the best approach. Braz Dent J. 1995;178:413-417

20. Taylor, P.R. An Illustrated History of Lost Wax Casting, Proceedings of the 17th Annual BICTA Conference; 1983.

21. Yau $\mathrm{WF}^{1}$, Cheng YY, Clark RK, Chow TW. Pressure and temperature changes in heat-cured acrylic resin during processing. Dent Mater. 2002 Dec; 18(8):622-9.

22. Klein M, Deforest A. The chemical inactivation of viruses. Fed.Proc. 1965;24:319.

23. Klein M., Deforest A. Principles of viral inactivation. In Disinfection, sterilization and preservation, 3rd Ed. (S.S. Block, ed.). Lea \& Febiger, Philadelphia. 1983; 422-434.

24. Mayaudon J., El-Zayat. The Mode Of Action And Cell Destruction Of Disinfectants. Chem. Mikrobiol. Technol. Lebensm. 1985; 9:11-13.

25. Scott F.W. Virucidal Disinfectants And Feline Viruses. Am. J. Vet. Res. 1979; 41:410-414.

26. Russell A.D. Principles Of Antimicrobial Activity. In Disinfection, Sterilization And Preservation, 3rd Ed. (S.S.Block, Ed.). Lea \& Febiger, Philadelphia.1983; 717-745

P. Maris. Modes Of Action Of Disinfectants. Rev. Sci. Tech. Off. Int. Epiz. 1995;14 (1): 47-55

27. Jagger DC, Harrison A. Denture cleansing-the best approach. Br Dent J. 1995; 178:413.

28. Nikawa H, Yamamoto $T$, Hamada $T$, Sadamori S, Agrawal S. Cleansing efficacy of commercial denture cleansers: Ability to reduce Candida albicans biofilm activity. Int J Prosthodont 1995; 8:527-534.

\section{How to cite this article:}

Fathima Mariyam Niyas et al (2017) ' Efficacy Of Povidone Iodine Vs Hydrogen Peroxide As Denture Disinfectants- In Vitro Study', International Journal of Current Advanced Research, 06(04), pp. 3451-3454.

DOI: http://dx.doi.org/10.24327/ijcar.2017.3454.0291 